\title{
HMGB1, a Novel Cytokine-Like Mediator Linking Acute Neuronal Death and Delayed Neuroinflammation in the Postischemic Brain
}

\author{
Jung-Bin Kim, ${ }^{1}$ Joon Sig Choi, ${ }^{2}$ Young-Mi Yu, ${ }^{1}$ Kihoon Nam,,${ }^{3}$ Chun-Shu Piao, ${ }^{1}$ Seung-Woo Kim, ${ }^{1}$ Min-Hyung Lee, ${ }^{4}$ \\ Pyung-Lim Han, ${ }^{5}$ Jong-sang Park, ${ }^{3}$ and Ja-Kyeong Lee ${ }^{1}$ \\ ${ }^{1}$ Department of Anatomy and Center for Advanced Medical Education (BK21 project), Inha University School of Medicine, Inchon 400-712, Korea, \\ ${ }^{2}$ Department of Biochemistry, Chungnam National University, Daejeon 305-764, Korea, ${ }^{3}$ School of Chemistry and Molecular Engineering, Seoul National \\ University, Seoul 151-742, Korea, ${ }^{4}$ Department of Bioengineering, School of Engineering, Hanyang University, Seoul 133-791, Korea, and ${ }^{5}$ Division of Nano \\ Sciences and Department of Life Sciences, Ewha Womans University, Seoul 110-783, Korea
}

Cerebral ischemic injury proceeds with excitotoxicity-induced acute neuronal death in the ischemic core and with delayed damage processes in the penumbra. However, knowledge concerning the direct mediators that connect these two processes is limited. Here, we demonstrate that high-mobility group box 1 (HMGB1), a nonhistone DNA-binding protein, is massively released into the extracellular space immediately after ischemic insult and that it subsequently induces neuroinflammation in the postischemic brain. Short hairpin (sh)RNA-mediated HMGB1 downregulation in the postischemic brain suppressed infarct size, microglia activation, and proinflammatory marker induction, indicating that HMGB1 plays a crucial role in the inflammatory process. The proinflammatory cytokine-like function of extracellular HMGB1 was further verified in primary cortical cultures and microglial cultures. HMGB1 was found to accumulate in NMDA-treated primary cortical culture media, and supernatants collected from these cultures were found to trigger microglia activation, the hallmark of brain inflammation. Moreover, treatment with recombinant HMGB1 also induced microglial activation, but HMGB1-depleted supernatant produced by anti-HMGB1 antibody treatment or by HMGB1 shRNA expression did not, thus demonstrating the essential role of HMGB1 in microglial activation. Together, these results indicate that HMGB1 functions as a novel proinflammatory cytokine-like factor that connects excitotoxicity-induced acute damage processes and delayed inflammatory processes in the postischemic brain.

Key words: HMGB1; MCA0; ischemia; inflammation; shRNA; PAMAM-Arg

\section{Introduction}

Cerebral ischemia leads to brain injury through a complex series of pathophysiological events, which result in neuronal death and subsequent neurological dysfunction. The major pathogenic mechanisms may include glutamate excitotoxicity, $\mathrm{Zn}^{+2}$ toxicity, peri-infarct depolarization, inflammation, and apoptosis. Excitotoxicity and $\mathrm{Zn}{ }^{+2}$ toxicity result in acute and massive neuronal death in the ischemic core (Lipton, 1999). A wealth of evidence suggests that this acute neuronal damage is followed by a second round of neuronal injury, called delayed neuronal death (Kirino, 2000). Of the many pathophysiological events that may contribute to this delayed injury, the cell-mediated processes associated with postischemic inflammation and apoptosis have been studied extensively (Graham and Chen, 2001). In particular, inflammatory reactions have been suggested to contribute to the late stages of ischemic injury and to result in a worsening of neurological outcome through multiple mechanisms, wherein

Received Sept. 8, 2005; revised April 11, 2006; accepted April 11, 2006.

This work was supported byKorea Science and Engineering Foundation Grant 2005-01096 to J.-K.L.

Correspondence should be addressed to Dr. Ja-Kyeong Lee, Department of Anatomy, Inha University School of

Medicine, 7-241 Shinheung-dong, Jung-Gu, Inchon 400-712, Republic of Korea. E-mail: jklee@inha.ac.kr.

DOI:10.1523/JNEUROSCI.3815-05.2006

Copyright $\odot 2006$ Society for Neuroscience $\quad$ 0270-6474/06/266413-09\$15.00/0 microglia plays a crucial role (Giulian, 1997; Dirnagl et al., 1999). However, it remains to be determined whether mediators connect the early acute neuronal death phase and delayed neuroinflammatory-related events in the postischemic brain.

High-mobility group box 1 (HMGB1) is a nonhistone DNAbinding protein that possesses two HMG boxes that are DNA binding domains (Landsman and Bustin, 1993). HMGB1 is widely expressed in various tissues including the brain. As a chromosomal protein, HMGB1 has been implicated in diverse intracellular functions, including the stabilization of nucleosomal structure and the facilitation of gene transcription (Bustin, 1999). Moreover, recent evidence identifies HMGB1 as a cytokine-like mediator of delayed endotoxin lethality and acute lung injury (Wang et al., 1999a; Abraham et al., 2000). HMGB1 is actively secreted by macrophages and monocytes or released by necrotic cells into the extracellular milieu, where it might be involved in the triggering of inflammation (Wang et al., 1999a; Abraham et al., 2000; Scaffidi et al., 2002; Bonaldi et al., 2003). Recombinant HMGB1 has been found to induce acute inflammation in animal models of lung injury and endotoxemia (Wang et al., 1999a; Abraham et al., 2000), and anti-HMGB1 antibody attenuated endotoxin-induced lethality even when administration of antibody was delayed until after early cytokine response (Wang et al., 
1999a; Yang et al., 2004). In addition, high serum levels of HMGB1 in patients with sepsis or hemorrhagic shock have been reported to be associated with increased mortality and disease severity (Ombrellino et al., 1999; Wang et al., 1999a). Moreover, in the brain, HMGB1 has recently been reported to be released after cytokine stimulation and to be involved in the inflammatory process after it was administered intracerebroventricularly (Wang et al., 1999b; Agnello et al., 2002).

The present study shows that HMGB1 is massively released during the excitotoxicity-induced acute damaging process in the postischemic brain and that extracellular HMGB1 triggers inflammatory processes, such as microglia activation. Thus, we provide evidence that HMGB1 acts as a novel mediator that links excitotoxicity-induced acute damage and subsequent inflammatory processes in the postischemic brain.

\section{Materials and Methods}

Surgical procedures for middle cerebral artery occlusion. All experiments were performed in accordance with the animal research guidelines issued by the Inha University School of Medicine. Male Sprague Dawley rats $(250-300 \mathrm{~g})$ were anesthetized with $5 \%$ isoflurane in a mixture of $30 \%$ oxygen and $70 \%$ nitrous oxide, and the middle cerebral artery (MCA) was occluded for $1 \mathrm{~h}$ using the suture occlusion method described previously (Longa et al., 1989; Kim et al., 2004). The left femoral artery was cannulated for monitoring arterial blood pressure (Blood Pressure Analyzer; Digi Med, Louisville, KY) and for blood sampling to analyze $\mathrm{pH}$, $\mathrm{PaO}_{2}, \mathrm{PaCO}_{2}$, and glucose concentration (I-STAT; Sensor Devises, Waukesha, WI). Regional cerebral blood flow was monitored using a laser Doppler flowmeter (Periflux System 5000; Perimed, Jarfalla, Sweden). A thermoregulated heating pad and an overhead heating lamp were used to maintain a rectal temperature of $37 \pm 0.5^{\circ} \mathrm{C}$. In sham-operated rats, an incision was made over the MCA, but the artery was not occluded.

Intracranial injection. Rats were anesthetized with an intramuscular injection (100-150 $\mu \mathrm{l} / 100 \mathrm{~g}$ body weight) of a mixture of ketamine and xylazine hydrochloride $(3: 1)$ and placed on a stereotaxic apparatus $(\mathrm{Na}-$ rishige Scientific Instrument Laboratory, Tokyo, Japan). The skull was leveled between bregma and lambda. The plasmid/arginine-grafted polyamidoamine dendrimer (PAMAM-Arg) complex $(10 \mu \mathrm{l})$ was injected stereotaxically into the striatum (coordinates in millimeters with reference to bregma: anteroposterior, 0 ; lateral, 5.0; ventral, 4.0) using a 26 gauge Hamilton microsyringe (80330; Hamilton, Reno, NV). Twomillimeter-thick coronal brain slices, which localized between 8 and 10 $\mathrm{mm}$ from the frontal pole, were taken from the brain using a brain matrix (RBM-40000; ASI Instruments, Houston, TX), and brain regions affected by short hairpin (sh)RNA-expressing plasmid were dissected. The tissue samples were kept at $-80^{\circ} \mathrm{C}$ until required.

Preparation of mixed neuron-glia cultures. Mixed cortical cells, including neurons and astrocytes, were prepared from embryonic day 15.5 mouse cortices and cultured as described by Kim et al. (2004). Dissociated cortical cells were plated at a density of five hemispheres per 24-well plate $\left(\sim 4 \times 10^{5}\right.$ cells per well $)$, which was poly-D-lysine $(100 \mu \mathrm{g} / \mathrm{ml})$ and laminin $(100 \mu \mathrm{g} / \mathrm{ml})$ coated. Cultures were maintained without antibiotics in minimal essential medium (MEM) with $5 \%$ fetal bovine serum (FBS) and 5\% horse serum. At $6 \mathrm{~d}$ in vitro (DIV), when astrocytes had reached confluence underneath neurons, cytosine arabinofuranoside was added to a final concentration of $10 \mu \mathrm{M}$ and the culture was maintained for $2 \mathrm{~d}$ to halt microglial growth. FBS and glutamine were not supplemented from day 6 , and the medium was changed twice per week after day 8. Cultures were used at 13-15 DIV.

Primary microglial culture. Primary microglial cultures were prepared as described previously. In brief, cells dissociated from the cerebral hemispheres of 1- to 3-d-old postnatal rat brains (Sprague Dawley strain) were seeded into $75 \mathrm{~cm}^{2}$ flasks at a density of $1.2 \times 10^{6}$ cells $/ \mathrm{ml}$ in MEM (Sigma, St. Louis, MO) containing 10\% FBS (Hyclone, Logan, UT). Culture media were changed after $24 \mathrm{~h}$ and then twice per week. After 2 weeks, microglia were then detached from the flasks by mild shaking and filtered through a nylon mesh to remove astrocytes. After centrifugation
$(1000 \times g)$ for $5 \mathrm{~min}$, the cells were resuspended in a fresh DMEM supplemented with $10 \%$ FBS and plated at a final density of $4 \times 10^{4}$ cells/well on a 24-multiwell culture dish. The following day, cells were subjected to different treatments. The microglial cultures used were $>96 \%$ pure.

NMDA and staurosporin treatment and cell supernatant preparation. Primary cortical cells were treated with serum-free MEM containing 30 $\mu \mathrm{M}$ NMDA (Sigma) and $10 \mu \mathrm{M}$ staurosporin (Sigma) for $1 \mathrm{~h}$. The medium was then removed and replaced with fresh MEM, and cells were cultured for $24 \mathrm{~h}$. Four hundred microliters of the culture medium were then collected and concentrated to $40 \mu \mathrm{l}$ by using Centricon 10 (Millipore, Billerica, MA) and either immunoblotted or used as a culture medium for activating primary microglial cultures.

Sampling of CSF. Rats were anesthetized, and the head was placed in a stereotaxic apparatus. The skin was incised, and the occipital bone was cleared of muscle to expose the atlanto-occipital membrane. A 27 gauge needle was inserted into the cisterna magna. When the tip of the needle was inserted 1-1.5 mm, reflux of the CSF was observed. Approximately $100 \mu \mathrm{l}$ of CSF was withdrawn.

Generation of the HMGB1 shRNA transgene. To generate shHMGB1pU6, two 64-mer sense and antisense oligonucleotides containing a 19 nucleotide inverted repeat corresponding to the HMGB1 coding region were synthesized (see Fig. 3A). The inverted motif, which also contained the seven-nucleotide spacer and five Ts (TTTTT), was subcloned into the Bam HI and HindIII sites, immediately downstream of the U6 promoter of the pU6 plasmid (Ambion, Austin, TX). A mutant plasmid, MshHMGB1U6, was constructed in the same way, except that six nucleotides within the target region were substituted. The sequences inserted were as follows (only the sense sequences are shown): shHMGB1, 5'-GATCCCGAAGCACCCGGATGCTTCTTTCAAGAGAAGAAGCATCCGGGTGCTTCTTTTTTGGAAA-3'; MshHMGB1, 5'-GATCCCGAAGCACTACTGCGCTTCTTTCAAGAGAAGAAGCGCAGTAGTGCTTCTTTTTTGGAAA-3'.

Transient transfections. All plasmids, including shHMGB1-pU6 and MshHMGB1-pU6, were mixed with PAMAM-Arg at a 1:3.5 charge ratio and administered to rat brain or transfected into primary cortical cultures. After $48 \mathrm{~h}$, cell or tissues were subjected to various biochemical assays.

$R N A$ preparation and reverse transcription- $P C R$. Total RNA was prepared using TRIzol reagent (Invitrogen, Gaithersburg, MD) according to the manufacturer's instructions, and $1 \mu \mathrm{g}$ RNA samples were used for cDNA synthesis. First-strand cDNA synthesis was primed with random hexamers and conducted according to the manufacturer's specifications (RT-PCR kit; Roche, Mannheim, Germany). The cDNA equivalent to $200 \mathrm{ng}$ of total RNA was subjected to PCR using the manufacturer's protocol (PCR core kit; Roche). The primer sequences of rat HMGB1, tumor necrosis factor- $\alpha(\mathrm{TNF} \alpha)$, interleukin- $\beta$ (IL-1 $\beta)$, inducible nitric oxide (iNOS), and cytochrome oxidase (COX)-2 have been described previously (Yu et al., 2003; Kim et al., 2004).

Northern analysis. Northern analysis was performed as described previously (Kim et al., 2004). Each lane was loaded with $50 \mu \mathrm{g}$ of total RNA. After being transferred to a nylon membrane (Roche), RNA blots were hybridized with a 64 bp DNA probe corresponding to HMGB1 shRNA. Probes were labeled with $\mathrm{P}^{32}$-dCTP using a random prime labeling system (Amersham Biosciences, Piscataway, NJ) and purified using a robeQuant G-50 micro column (Amersham Biosciences). A total of $1 \times 10^{7}$ cpm of labeled probe was applied to each membrane in hybridization buffer (ULTRAhyb; Ambion) and incubated at $42^{\circ} \mathrm{C}$ for $18 \mathrm{~h}$. Membranes were washed and exposed to film.

2,3,5-Triphenyl tetrazolium chloride staining. Rats were decapitated after $2 \mathrm{~d}$ of reperfusion, and entire brains were dissected coronally into 2 $\mathrm{mm}$ brain slices using a metallic brain matrix (RBM-40000; ASI Instruments). Slices were immediately stained by immersion in $1 \% 2,3,5$ triphenyl tetrazolium chloride (TTC) at $37^{\circ} \mathrm{C}$ for $15 \mathrm{~min}$ and then in $4 \%$ paraformaldehyde for preservation.

Lectin histochemistry. Vibratome sections were incubated with horseradish peroxidase (HRP)-conjugated Griffonia simplicifolia isolectin- $\mathrm{B}_{4}$ $\left(\right.$ GSA I-B $\left.{ }_{4}\right)$ (Sigma) at $10 \mu \mathrm{g} / \mathrm{ml}$ in PBS at room temperature for $3 \mathrm{~h}$. After three washes in $\mathrm{PBS}$, isolectin binding sites were visualized using $\mathrm{HRP} / 3,3^{\prime}$-diaminobenzidine. 

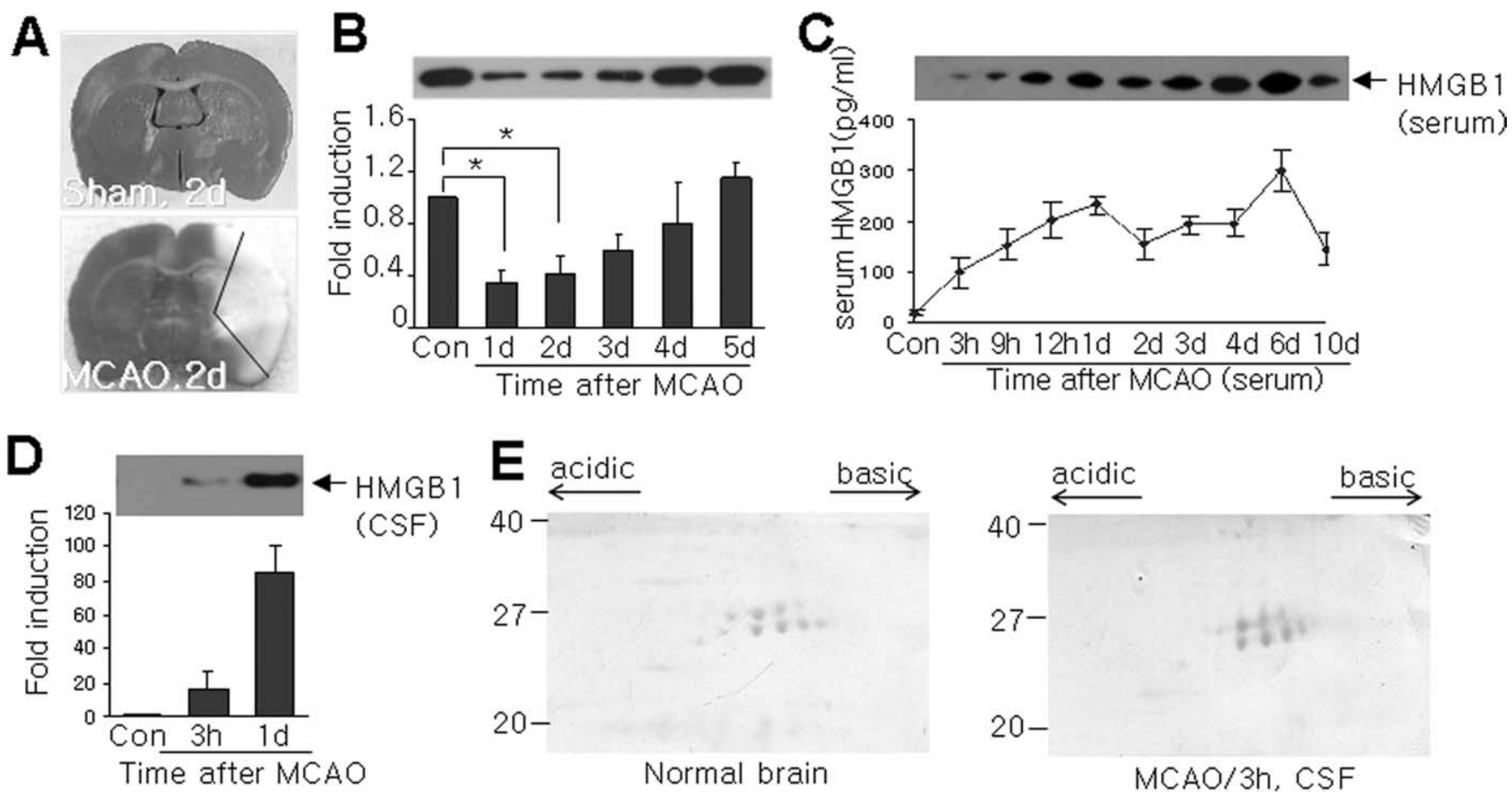

Figure 1. Plasma and CSF HMGB1 immediately increased after MCAO. A, TTC staining was performed with coronal brain sections, which were obtained $2 \mathrm{~d}$ after sham operation or after $1 \mathrm{~h}$ of MCAO. B, HMGB1 levels in ischemic hemispheres (indicated region in bottom panel in $\boldsymbol{A}$ ) were determined by immunoblotting at various times after $1 \mathrm{~h}$ of MCAO. $\boldsymbol{C}, \boldsymbol{D}, \mathrm{HMGB}$ levels in serum $(\boldsymbol{C})$ and in CSF (D) were examined by immunoblotting. $\boldsymbol{E}$, Total protein extracts obtained from normal brain tissue or from CSF after MCAO were loaded onto two-dimensional gels, blotted, and immunodetected with anti-HMGB1 antibody. Data are presented as means \pm SEM $(n=3) .{ }^{*} p<0.05$.

5-Bromo-4-chloro-3-indolyl- $\beta$-D-galactopyranoside histochemistry. Animals were perfused transcardially with $4 \%$ paraformaldehyde, and brain slices (50 $\mu \mathrm{m}$ thick) were prepared. After three washes in $0.01 \%$ sodium deoxycholate, $0.02 \%$ Nonidet P-40, $2 \mathrm{mM} \mathrm{MgCl}_{2}$, and $0.1 \mathrm{M} \mathrm{NaHPO}_{4}, \mathrm{pH}$ 7.3, 5-bromo-4-chloro-3-indolyl- $\beta$-D-galactopyranoside (X-gal) staining was performed over $12-16 \mathrm{~h}$ at $37^{\circ} \mathrm{C}$ in $\mathrm{X}$-gal buffer $\left[2 \mathrm{mM} \mathrm{MgCl}_{2}, 5\right.$ $\mathrm{mm} \mathrm{K}_{3} \mathrm{Fe}(\mathrm{CN})_{6}, 5 \mathrm{~mm} \mathrm{~K}_{4} \mathrm{Fe}(\mathrm{CN})_{6}, 0.1 \mathrm{~mm} \mathrm{NaHPO}_{4}$, $\mathrm{pH} 7.3,0.01 \%$ sodium deoxycholate, and $0.02 \%$ Nonidet P-40] containing $1 \mathrm{mg} / \mathrm{ml} \mathrm{X-gal}$.

Two-dimensional gel electrophoresis. Seven-centimeter linear $\mathrm{pH}$ 3-10 non-linear immobilized $\mathrm{pH}$ gradient strips were loaded with proteins by passive rehydration overnight. Isoelectric focusing was performed on an IPGphor device (Amersham Biosciences) and was performed up to a total of $66 \mathrm{kVh}$. The IPG strips were rinsed thoroughly with distilled water and quickly dried on filter paper, and focused proteins were reduced (50 mu Tris/HCl, pH 6.8, $6 \mathrm{~m}$ urea, 2\% w/v SDS, 30\% v/v glycerol, and $2 \% \mathrm{w} / \mathrm{v} \mathrm{DTT}$ ) and alkylated (50 mm Tris/ $\mathrm{HCl}, \mathrm{pH} 6.8,6 \mathrm{~m}$ urea, $2 \%$ $\mathrm{w} / \mathrm{v}$ SDS, 30\% v/v glycerol, and $4.5 \% \mathrm{w} / \mathrm{v}$ iododacetamide) for $20 \mathrm{~min}$ each. Strips were then placed on top of $12 \%$ SDS- polyacrylamide gels and ran at $25 \mathrm{~mA}$ constant current per gel.

Immunoblotting. Brain homogenates were immunoblotted as described previously (Kim et al., 2004). Rats were deeply anesthetized with an overdose of sodium pentobarbital (100 mg/kg, i.p.), and brain slices were prepared as described above. Blood samples $(1 \mathrm{ml})$ were drawn by cardiac puncture after $15 \mathrm{~min}$ of centrifugation at $1500 \times \mathrm{g}$, and serum was collected and stored at $-80^{\circ} \mathrm{C}$ in sterile polypropylene tubes until required for assay. Tissue and serum samples were incubated in $50 \mathrm{~mm}$ HEPES, $\mathrm{pH} 7.4,0.1 \%$ Nonidet $\mathrm{P}-40$, and $150 \mathrm{~mm} \mathrm{NaCl}$ supplemented with a protease inhibitor mixture (BD Biosciences, Franklin Lakes, NJ) for $15 \mathrm{~min}$ on ice and centrifuged at $6000 \times g$ at $4^{\circ} \mathrm{C}$. Protein concentrations were determined using Bradford's method (Bio-Rad, Hercules, CA). Lysates were incubated for $10 \mathrm{~min}$ in the presence of SDS sample buffer containing 2-mercaptoethanol and centrifuged at $16,000 \times g$ for 5 $\min$ at $4^{\circ} \mathrm{C}$, and supernatants were loaded onto SDS-PAGE. Primary antibodies were diluted as follows, 1:1000 for anti-HMGB1 (BD Bioscience) and 1: 500 for p38 mitogen-activated protein kinase (MAPK) and phospho-p38 MAPK, and detected by using a chemiluminescence kit (BD Bioscience) using donkey anti-rabbit HRP-conjugated secondary antibody (Pierce, Rockford, IL).

NO measurement. Primary microglia $\left(4 \times 10^{4}\right)$ plated on 24-well plates were treated with lipopolysaccharide (LPS) $(100 \mathrm{ng} / \mathrm{ml})$ for $48 \mathrm{~h}$. To measure the amount of NO produced by microglia, $100 \mu \mathrm{l}$ of conditioned medium was mixed with an equal volume of Griess reagent $(0.5 \%$ sulfanilamide and $0.05 \% \mathrm{~N}$-1-naphthylethylenediamine) and incubated for $10 \mathrm{~min}$ at room temperature. Absorbance of the mixture at $550 \mathrm{~nm}$ was measured using a microplate reader.

HMGB1 measurements. Serum samples or cell-conditioned media were fractionated by SDS-PAGE, and HMGB1 levels were determined by immunoblotting using a standard curve for recombinant HMGB1 as a reference (Sigma). Briefly, serum samples or cell-conditioned media (100-200 $\mu \mathrm{l}$ ) were ultrafiltered using a Centricon 10 (Millipore), fractionated by SDS-PAGE, and transferred to polyvinylidene difluoride membranes (Bio-Rad). The primary antibodies for anti-HMGB1 (BD Bioscience) and anti-histone (Chemicon, Temecula, CA) were diluted 1:1000 and 1:500, respectively. Detection was performed using a chemiluminescence kit (BD Bioscience).

Treatment of recombinant HMGB1. Primary microglia $\left(4 \times 10^{4}\right)$ plated on 24-well plates were treated with various amounts of recombinant human HMGB1 (rhHMGB1) (Sigma). At different time points, cells and cell supernatants were harvested and used in reverse transcription (RT)-PCR and Griess assay, respectively. The endotoxin content of rhHMGB1 was determined with a standard endotoxin-specific Limulus amebocyte lysate reagent (Endosafe, Wilmington, MA). Endotoxic content was always $<0.05 \mathrm{EU} / \mathrm{ml}$.

\section{Results}

\section{Plasma HMGB1 rapidly increases after transient focal} cerebral ischemia

We observed that the HMGB1 level in the infarction area in ipsilateral sides (Fig. 1A, bottom) significantly declined at $1 \mathrm{~d}$ after MCA occlusion (MCAO)/reperfusion to below the basal level (Fig. $1 B$ ). HMGB1 levels gradually increased over $4 \mathrm{~d}$ to above 
basal levels (Fig. $1 B$ ). In contrast, plasma HMGB1 levels rapidly increased from $3 \mathrm{~h}$ after $1 \mathrm{~h}$ of MCAO, continued to increase for $6 \mathrm{~d}$ (Fig. 1C), and then declined slowly. Rapid HMGB1 accumulation was also detected in CSF $3 \mathrm{~h}$ after MCAO, and further accumulation was observed at $1 \mathrm{~d}$ after MCAO (Fig. 1D). To examine whether HMGB1 in CSF is hyper-acetylated, as is the case for HMGB1, which is actively secreted by other cell types (Bonaldi et al., 2003), two-dimensional electrophoresis was performed on proteins purified from CSF obtained $3 \mathrm{~h}$ after MCAO. The patterns of HMGB1 spots detected on blots were similar to those obtained for normal brain tissue, and no hyper-acetylated spot was present (Fig. $1 E$ ), indicating that the rapid accumulation of HMGB1 in the CSF was not achieved by active secretion but probably by passive release.

\section{shRNA-mediated suppression of HMGB1 expression in the brain}

To investigate the functional significance of the rapid accumulation of HMGB1 in the serum and CSF of the postischemic brain, we knocked down HMGB1 mRNA using a plasmid expressing the shRNA of the HMGB1 gene. The hairpin-forming $64 \mathrm{bp}$ insert in this plasmid (shHMGB1-pU6) harbors an inverted repeat of 19 bp corresponding to the HMGB1 coding region, into which a $7 \mathrm{bp}$ spacer was inserted between the inverted sequences (Fig. 2A). A mutant shHMGB1-expressing plasmid, containing a sixnucleotide substitution within the 19 bp region, was also constructed (MshHMGB1-pU6). A novel cationic polymer, PAMAM-Arg, which was generated by conjugating primary amines located on the surface of PAMAM dendrimer with L-arginine (Choi et al., 2004), was used as a gene carrier. We reported previously that PAMAM-Arg enables high transfection efficiencies in a neuronal cell line, Neuro 2A (Choi et al., 2004), and in primary cortical cells (Kim et al., 2006).

The extent of the diffusion of the injected plasmid from the needle path was approximated by injecting a mixture of a lac $Z$ expressing plasmid and PAMAM-Arg and then $\beta$-gal staining (Fig. 2A, left). Northern blot analysis of a sample from the plasmid-affecting area (Fig. $2 B$, white box in the right panel) revealed the presence of the shRNA transcript at $24 \mathrm{~h}$ after injection and its persistence for $>7 \mathrm{~d}$ (Fig. $2 C$ ). Moreover, this shRNA was found to suppress endogenous HMGB1 expression to $56.3 \pm$ $8.9 \%(n=3 ; p<0.05)$ of the control level on day 4 , but then HMGB1 expression recovered gradually to its baseline level at $10 \mathrm{~d}$ after injection (Fig. 2D). In contrast, HMGB1 expression was unaffected in mutant shRNA-expressing plasmid (MshHMGB1-pU6)-administered animals (Fig. 2D), thus demonstrating the specificity of shHMGB1-pU6 plasmid and alleviating concerns about the possible toxic effects of PAMAM-Arg and injected plasmid.

shRNA-mediated HMGB1 suppression had a neuroprotective effect in the postischemic brain

The shHMGB1/pU6/PAMAM-Arg complex was administered $24 \mathrm{~h}$ before the $1 \mathrm{~h}$ of MCAO, into the striatum, which encom- passes infarction core later (Fig. 3C, top left). Serum HMGB1 levels were found to be significantly reduced (Fig. $3 A$ ), and the suppressive effect of shRNA was sustained for $10 \mathrm{~d}$ by a single administration of shHMGB1-pU6 plasmid (Fig. 3A), which agrees well with the observed duration of shRNA expression (Fig. $2 C)$. The administration of shHMGB1-pU6 plasmid also repressed delayed HMGB1 induction in the infarct core (Fig. $1 B$ ), but this was not detected in animals administered MshHMGB1pU6 (Fig. 3B). Moreover, TTC(TTC) staining revealed that shHMGB1-pU6 administration at $24 \mathrm{~h}$ before MCAO significantly suppressed infarct volumes in 21 of 23 animals (Fig. 3D). Seventy-six percent of shHMGB1-pU6-administered animals exhibited infarct suppression along the syringe path $(>70 \%$ suppression of infarct; type I) (Fig. $2 \mathrm{~B}$, white box region), and the remainder showed infarct suppression in the entire striatum (type II) (Fig. 3C). In contrast, no infarct suppression (type III) was observed in animal administered MshHMGB1-pU6 (Fig. $3 D)$.

\section{Anti-inflammatory effect of HMGB1 suppression in the postischemic brain}

Microglia activation is a hallmark of brain inflammation. The numbers of activated or phagocytic microglia were notably increased $4 \mathrm{~d}$ after $1 \mathrm{~h}$ of MCAO (Fig. $4 B$, E, black box in the inset in Fig. $4 A$ ), but not in animals pre-administered shHMGB-pU6, which showed relatively few ramified microglia in the infarction core (Fig. 4C,E). In contrast, numerous activated or phagocytic microglia were detected in animals administered MshHMGBpU6 (Fig. $4 D, E$ ), thus indicating an anti-inflammatory effect of HMGB1 suppression in the postischemic brain. In addition, p38 MAPK activation (detected as the phosphorylated form) was significantly suppressed in shHMGB-pU6-administered animals (Fig. $4 F$, small box in the inset in Fig. $4 A$ ). Moreover, the inductions of the proinflammatory factors TNF- $\alpha$, IL- $1 \beta$, COX-2, and iNOS were repressed in the injected area (Fig. $4 A$, inset, small 


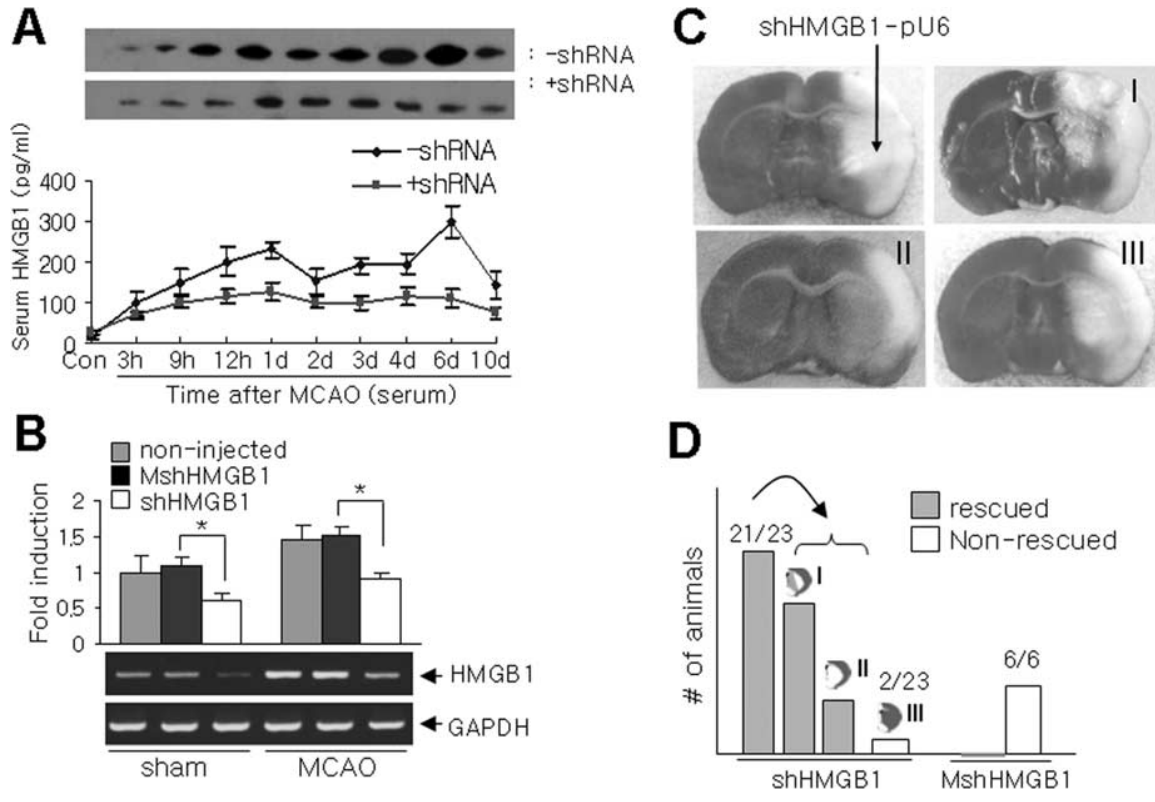

Figure 3. Neuroprotection by the shRNA-mediated silencing of HMGB1 induction in the postischemic brain. shHMGB1-pU6/ PAMAM-Arg or MshHMGB1-pU6/PAMAM-Arg complexes were administered into the indicated region (C) $24 \mathrm{~h}$ before $1 \mathrm{~h}$ of MCAO. $A$, The serum levels of HMGB1 in shHMGB1-pU6-administered animals were determined by immunoblotting at the indicated times after $1 \mathrm{~h}$ of MCA0. $B$, The levels of HMGB1 in the brain tissues (Fig. 2B, right, white box) of shHMGB1-pU6- or MshHMGB1-pU6administered animals were determined by RT-PCR24 $\mathrm{h}$ after $1 \mathrm{~h}$ of MCAO . C, A TTC-stained infarction area in a coronal brain section $2 \mathrm{~d}$ after $1 \mathrm{~h}$ of MCA0. The arrow indicates the administration point of the shHMGB1-pU6/PAMAM-Arg complex $24 \mathrm{~h}$ before $1 \mathrm{~h}$ of MCA0. Representative pictures showing suppressed infarct formation (types I and II) and no suppression (type III) are presented. $D$, Numbers of rescued or nonrescued animals are presented in the bar graph. Data are presented as means \pm SEM $(n=3) .{ }^{*} p<$ 0.05 .

box) $24 \mathrm{~h}$ after $\mathrm{MCAO} /$ reperfusion (Fig. $4 G-K$ ), indicating that HMGB1 plays a role in proinflammatory molecule release during this stage. Together, these results indicate that HMGB1 suppression has an anti-inflammatory effect in the postischemic brain.

\section{Massive HMGB1 release after excitotoxicity-induced neuronal cell death in primary cortical cultures}

We next investigated the function of extracellular HMGB1, which accumulates during the acute damaging stage in the postischemic brain, using primary cortical cultures. Levels of HMGB1 in the cell homogenates and supernatants of primary cortical cultures were measured after NMDA, glutamate, or staurosporin treatment. Under normal conditions, HMGB1 was exclusively localized to the nuclei of neurons and astrocytes (data not shown). Interestingly, HMGB1 was found to accumulate in culture medium after incubating primary cortical cells with NMDA for $24 \mathrm{~h}$ (Fig. 3A), and a similar enrichment of HMGB1 was observed for glutamate-treated culture medium (Fig. $5 B$ ). These results indicate that HMGB1 is rapidly released into the extracellular space after excitotoxicity-induced neuronal death. However, in marked contrast, HMGB1 levels in staurosporine-treated cells were increased in cell homogenates but not in medium (Fig. $5 C)$. In all cases, no histone was detected in culture medium, and its levels in cell homogenates were unaffected by these treatments (Fig. 5).

\section{Activation of microglia by extracellular HMGB1}

To examine whether HMGB1 released into excitotoxin-treated cell supernatants is capable of triggering microglial activation, primary microglia cultures were incubated with media collected from NMDA-treated primary cortical cells. To remove residual NMDA in supernatant, cells were cultured in fresh medium after being exposed to NMDA $(30 \mu \mathrm{M})$ for $1 \mathrm{~h}$. Supernatants obtained from NMDAtreated cortical cultures were found to induce microglial activation, as demonstrated by NO secretion (Fig. 6A). However, NMDA-treated supernatants complemented with anti-HMGB1 antibody showed no microglial activation (Fig. 6A), indicating that HMGB1 in medium plays an important role in microglial activation. Regardless of the presence of anti-HMGB1 antibody, staurosporintreated cell supernatant was incapable of activating microglia (Fig. 6A). Moreover, NMDA-induced HMGB1 release into culture medium was notably reduced in shHMGB1-pU6-transfected cells but not in MshHMGB1-pU6-transfected cells (Fig. 6B), and as was expected, supernatants from shHMGB1-pU6-expressing primary cortical cells were incapable of activating microglia (Fig. 6C), further supporting the notion that HMGB1 in culture medium plays a crucial role in microglial activation. In addition, microglial activation by excitotoxin-treated cell supernatant was further confirmed by the marked inductions of proinflammatory markers [e.g., iNOS, interferon $\gamma$ (IFN $\gamma$ ), COX-2, and TNF $\alpha$ ) (Fig. 6D). As was expected, supernatants from shHMGB1-pU6expressing primary cortical cells were incapable of inducing proinflammatory markers (Fig. 6D). Together, these results demonstrate that extracellular HMGB1 released by excitotoxintreated neurons plays a crucial role in microglial activation in vitro (Fig. 6) and in vivo (Fig. 4).

Purchased rhHMGB1 dose-dependently induced microglial NO release, and this effect was maximal at $500 \mathrm{ng} / \mathrm{ml}$ (Fig. $7 A, B$ ). Marked proinflammatory factor induction was also observed in rhHMGB1-treated cells, and the levels of proinflammatory factor induction at different rhHMGB1concentrations paralleled those of $\mathrm{NO}$ release (Fig. 7C). Moreover, the amount of $\mathrm{NO}$ released from rhHMGB1-treated cells was lower than those released from LPS- or IFN $\gamma$-treated cells (Fig. 7D), which were treated with low doses of LPS $(50 \mathrm{ng} / \mathrm{ml}), \operatorname{IFN} \gamma(25 \mathrm{ng} / \mathrm{ml})$ or TNF $\alpha(50 \mathrm{ng} / \mathrm{ml})$ to examine synergistic interactions. Interestingly, cotreatment with a battery of proinflammatory cytokines revealed that rhHMGB1 appeared to act synergistically with IFN $\gamma$ to drive NO release (Fig. 7D).

\section{Discussion}

The present study demonstrates that HMGB1 is massively released into the extracellular milieu during the acute damaging phase and that HMGB1 connects acute excitotoxicity-induced neuronal death to delayed damaging processes, such as inflammation, in the postischemic brain. Extracellular HMGB1 might function as a proinflammatory cytokine, activate microglia, and hence stimulate the release of other cytokines and aggravate brain injury. Therefore, the shHMGB1-mediated protective effect shown in Figure 3 might be derived from a reduction in the amount of HMGB1 released during the acute phase. This suggestion is in accord with previous studies that reported Hmgb1 ${ }^{-/-}$ necrotic cells have a greatly reduced ability to promote inflam- 


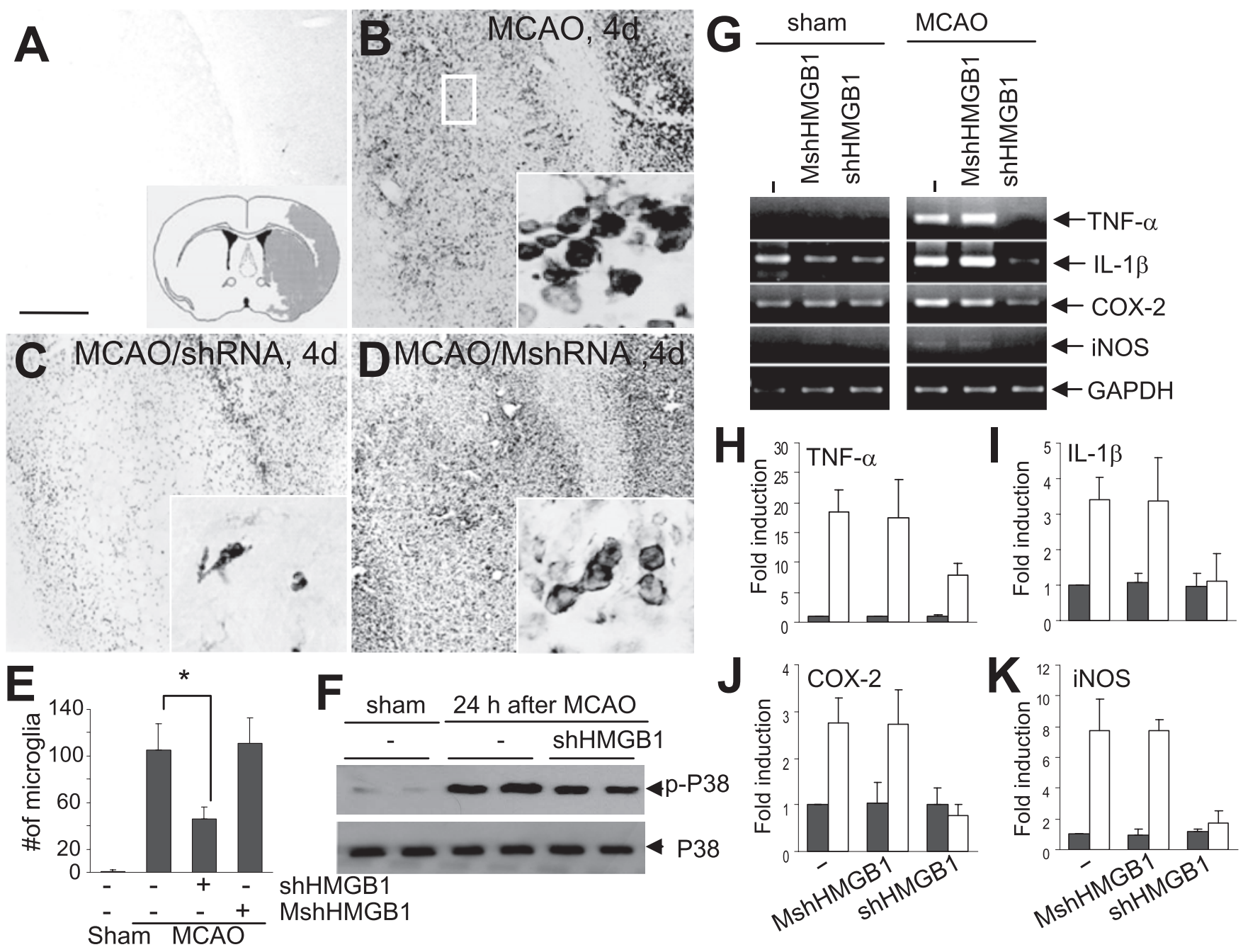

Figure 4. Suppression of inflammatory markers by HMGB1 shRNA in the postischemic brain. $A-D$, Microglia activation $4 \mathrm{~d}$ after $1 \mathrm{~h}$ of MCAO was visualized by anti-GSA I- $B_{4}$ immunostaining (large rectangle area in the inset in $\boldsymbol{A})$. shHMGB1-pU6 $(\boldsymbol{C})$ or MshHMGB1-pU6 (D) was administered $24 \mathrm{~h}$ before MCA0. Activated microglia were detected in the ischemic core $(\boldsymbol{B})$. Activated microglia numbers were notably reduced in wild-type shRNA-expressing brains $(\boldsymbol{C})$ but not in mutant shRNA-expressing brains $(\boldsymbol{D})$. The insets in $\boldsymbol{A}-\boldsymbol{D}$ are high-magnification micrographs. $\boldsymbol{E}$, The numbers of

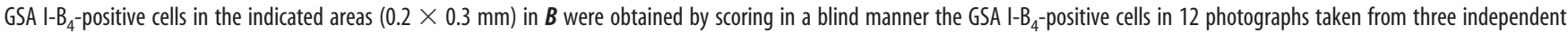
experiments. $\boldsymbol{F}$, Activation of p 38 MAPK was examined $24 \mathrm{~h}$ after $1 \mathrm{~h}$ of MCAO by immunoblotting using anti-phosphorylated p38 MAPK antibody. $\mathbf{G}-\boldsymbol{K}$, The expressions of proinflammatory markers in the presence of shHMGB1-pU6 or MshHMGB1-pU6 were examined $1 \mathrm{~d}$ after $1 \mathrm{~h}$ of MCA0. Solid bars, Sham; open bars, MCAO (H-K). Data are presented as means \pm SEM $(n=3)$. ${ }^{*} p<0.05$. Scale bar: $A-D, 500 \mu \mathrm{m}$. GAPDH, Glyceraldehyde-3-phosphate dehydrogenase.

mation (Scaffidi et al., 2002). Recently, Tsung et al. (2005) reported that HMGB1 appears to mediate hepatic injury after murine liver ischemia/reperfusion, wherein HMGB1 modulates inflammatory signaling pathways.

Excitotoxicity is a leading cause of neuronal death after focal cerebral ischemia. The activation of glutamate receptors, by the attendant failure of ion homeostasis and increase in intracellular $\mathrm{Ca}^{2+}$ concentrations, is a major factor in the initiation of ischemic cell death (Dirnagl et al., 1999). Because early increases in plasma HMGB1 levels were suppressed by HMGB1 shRNA (Fig. $3 A$ ) and HMGB1 was released in glutamate- or NMDAchallenged primary cortical cultures (Fig. 5), HMGB1 release during acute excitotoxic insults in the postischemic brain might be derived from neurons. Furthermore, we observed the rapid disappearance of HMGB1-positive neurons but not of HMGB1positive glia in infarct core at $3 \mathrm{~h}$ after MCAO (J. B. Kim and J. K. Lee, unpublished data). A massive release of HMGB1 from damaged neurons would serve as a danger signal and evoke inflammatory reactions, such as the activations of glial cells, various blood immune cells, and endothelial cells. The mediator-like function of HMGB1 with respect to linking early and secondary damaging processes in the postischemic brain might also be relevant to other neuropathological conditions, such as epilepsy and spinal cord injury, which also involve similar delayed progresses after acute and massive neuronal death (Rosenzweig and McDonald, 2004; Weise et al., 2005). We found that the preadministration of the HMGB1 shRNA-expressing plasmid shHMGB1pU6 (the same plasmid as used in the present study) into the hippocampal CA3 region of mouse brain prominently suppressed kainic acid-induced neuronal death and after gliosis (S. W. Kim, J. B. Kim, J. K. Lee, unpublished observation). The above results also support the notion that HMGB1 functions as a proinflammatory cytokine in the CNS.

Although the mechanism by which HMGB1 exerts its proinflammatory cytokine-like effects in the CNS is unknown, the results of the present study indicate that HMGB1 directly triggers microglial activation probably by directly activating signaling cascades and that it also indirectly regulates the expressions of 


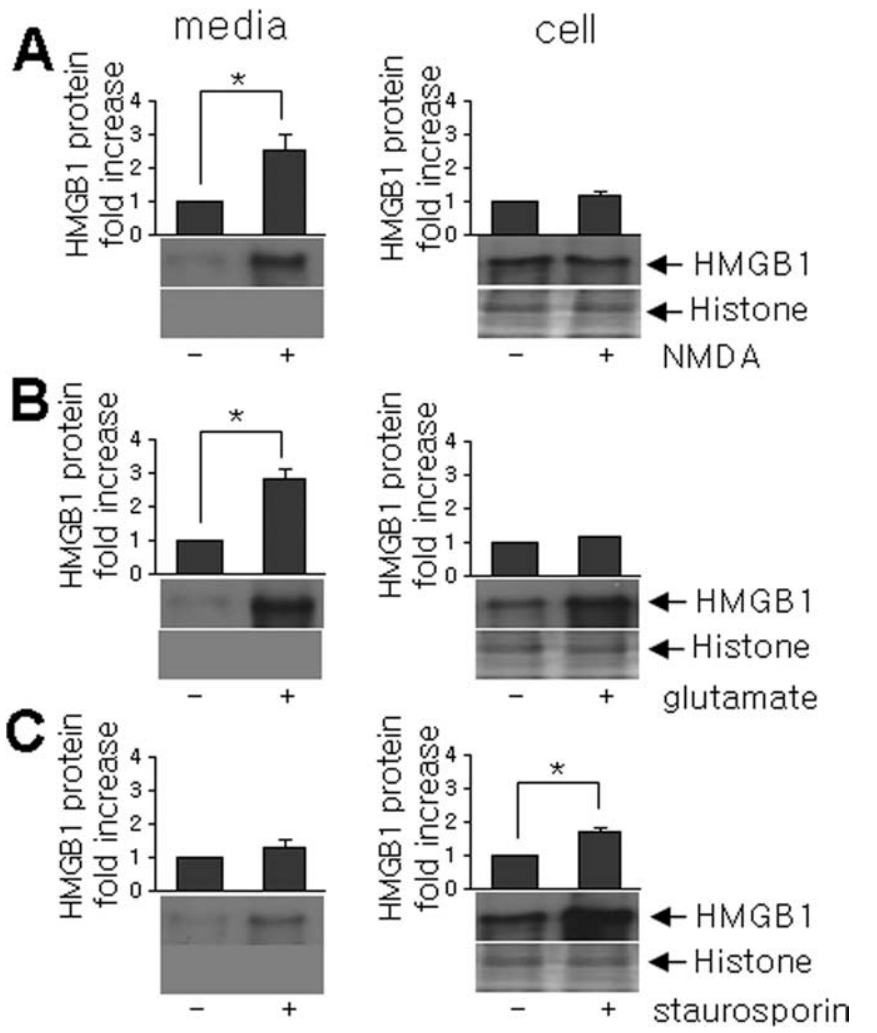

Figure 5. Accumulation of HMGB1 in bath medium containing primary cortical cell cultures undergoing excitotoxicity-induced cell death. Primary cortical cultures were incubated in serum-free MEM containing $30 \mu \mathrm{m} \operatorname{NMDA}(\boldsymbol{A}), 50 \mu \mathrm{m}$ glutamate $(\boldsymbol{B})$, or $10 \mu \mathrm{m}$ staurosporin (C) for $1 \mathrm{~h}$. After $24 \mathrm{~h}$, both culture media and cell homogenates were analyzed by immunoblotting with anti-HMGB1 or anti-histone antibody $(\boldsymbol{A}-\boldsymbol{C})$. Data are presented as means $\pm \operatorname{SEM}(n=3)$. ${ }^{*} p<0.05$.

classic proinflammatory cytokines. The present and other reports show that the activations of several MAPKs and nuclear factor $\kappa \mathrm{B}$ $(\mathrm{NF}-\kappa \mathrm{B})$ are involved in the proinflammatory effect of HMGB1 (Huttunen et al., 1999; Taguchi et al., 2000; Park et al., 2003) (Fig. $4 F$ ). These are downstream molecules of RAGE (receptor for advanced glycation end product) or toll-like receptor family members, which are important receptors in the HMGB1 signaling process (Schmidt et al., 2000; Huttunen and Rauvala, 2004; Park et al., 2004; Tsung et al., 2005). Although we found that RAGE, TRL2, and TRL4 are present in microglia (data not shown), interactions between them and the relative contributions they make to different signaling pathways require additional investigation. In addition, the inductions of proinflammatory factors by HMGB1 were notable in vivo (Fig. $4 G-K$ ) and in vitro (Fig. $6 D$ ). We believe that HMGB1 functions synergistically with other cytokines, particularly with IFN $\gamma$ during NO production in activated microglia. Synergistic effects could be achieved by HMGB1 secretion upregulation by IFN $\gamma$ or by IFN $\gamma$ secretion upregulation by HMGB1, as has been described in natural killer cells (DeMarco et al., 2005).

Despite the fact that the level of HMGB1-induced NO release in microglia was relatively low compared with those induced by LPS or IFN $\gamma$, reductions in infarct sizes and inflammatory process suppressions were remarkable in the HMGB1 shRNAexpressing brain (Fig. 3). This may be because extracellular HMGB1 in vivo acts on target cells other than microglia. HMGB1 potently stimulates the release of various proinflammatory cytokines in cultured macrophages, monocytes, or neutrophils

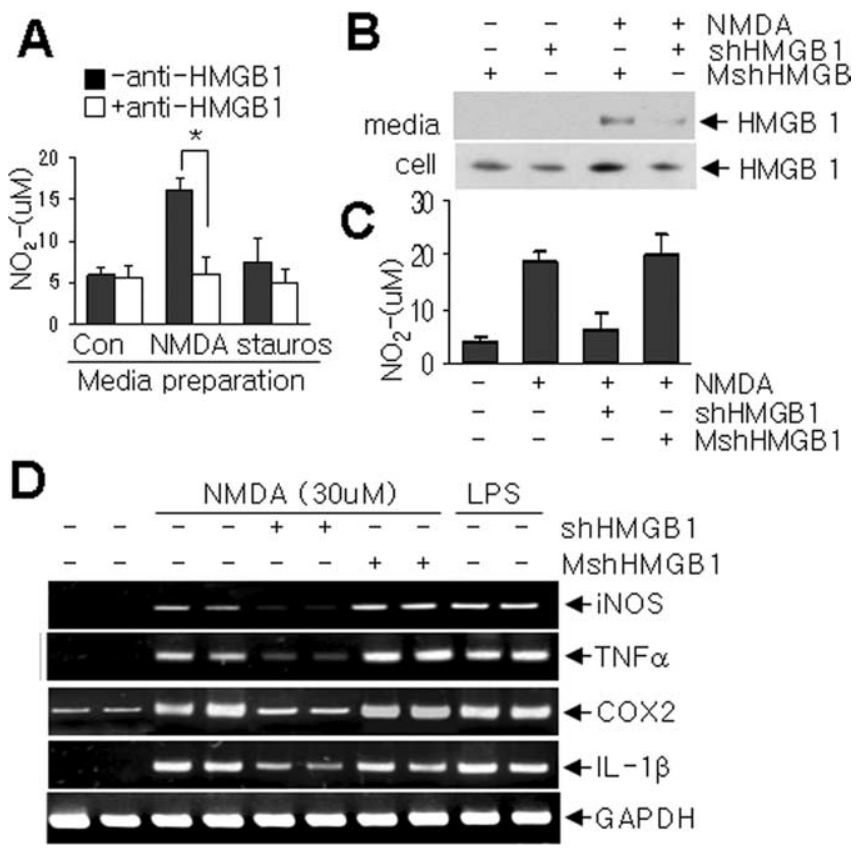

Figure 6. Microglial activation by extracellular HMGB1. A, Primary microglial cultures $(1 \times$ $10^{4}$ cells) were incubated with media collected from NMDA- or staurosporine (stauros)-treated primary cortical cultures for $24 \mathrm{~h}$ in the presence or absence of anti-HMGB1 antibody, and N0 production was determined using the Griess method. shHMGB1-pU6 or MshHMGB1-pU6 was transiently transfected into primary cortical cells $24 \mathrm{~h}$ before NMDA treatment. Con, Control. $\boldsymbol{B}$, The amounts of HMGB1 in NMDA-treated cells and in medium bathing were determined by RT-PCR after $24 \mathrm{~h}$ of NMDA treatment. C, Primary microglia cultures were treated with media collected from NMDA-treated primary cortical cultures, transfected or not transfected with shRNA-expressing plasmid or mutant shRNA-expressing plasmid, and N0 production was determined using the Griess method. $\boldsymbol{D}$, Changes in the RNA levels of the proinflammatory markers TNF- $\alpha$, COX-2, and IL-1 $\beta$ in the presence of HMGB1 shRNA-expressing plasmid or of mutant shRNA-expressing plasmid were followed by RT-PCR. LPS (100 ng/ml) treatment was used as a positive control. GAPDH, Glyceraldehyde-3-phosphate dehydrogenase. The results of four independent experiments are presented as means \pm SEM.

(Andersson et al., 2000; Park et al., 2003). In addition, the activation of human microvascular endothelial cells by HMGB1 has been reported to result in the inductions of various adhesion molecules, proinflammatory cytokines, and RAGE and in the activations of MAPKs and NF- $\kappa$ B (Fiuza et al., 2003; Treutiger et al., 2003). Therefore, HMGB1 might function pleiotropically, and its effects may be interconnected and affect various target cells in vivo. For that reason, inhibition of HMGB1 by shRNA at early time points might influence neighboring cells, although detailed a mechanism needs to be explored, so that protected brain tissue could be extended beyond the shRNA-injected area (Fig. $3 C, D)$.

In the present study, we found that rapidly accumulating HMGB1 in CSF is not hyper-acetylated (Fig. $1 E$ ), indicating that it is not actively secreted but rather released from damaged cells. However, in view of the findings that serum HMGB1 levels were sustained for $10 \mathrm{~d}$ after reperfusion and that serum HMGB1 levels showed a delayed surge at around $6 \mathrm{~d}$ after $1 \mathrm{~h}$ of MCAO (Fig. $1 C)$, HMGB1 might also be actively secreted by inflammatory cells subject to delayed activation in the postischemic brain. In this regard, we observed HMGB1 induction in phagocytic microglia in the infarction core 3-4 d after MCAO/reperfusion (data not shown), which might be responsible for the observed delayed surge in HMGB1 levels in ischemic hemispheres (Fig. 1B). HMGB1 is highly acetylated by nuclear acetyltransferase before secretion, whereas passively released HMGB1 is not acetylated 


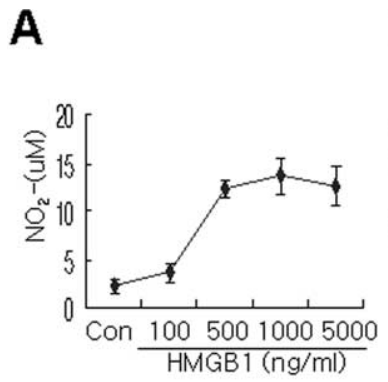

B
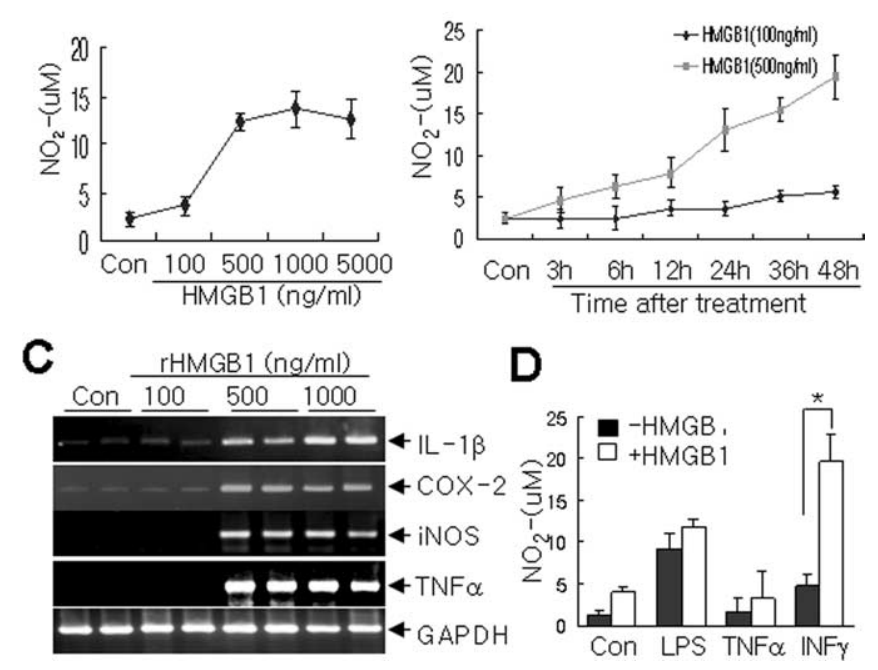

D

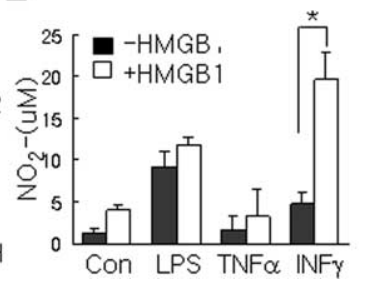

Figure 7. Induction of microglia activation by recombinant HMGB1. $A, B$, Primary microglia cultures were treated with the indicated concentrations of rHMGB1 for $48 \mathrm{~h}(\boldsymbol{A})$ or treated with 100 or $500 \mathrm{ng}$ of rHMGB1 for the indicated times $(\boldsymbol{B})$, and N0 production was determined by measuring nitrite in medium using the Griess method. $\boldsymbol{C}$, Changes in the RNA levels of the pro-inflammatory markers iNOS, TNF- $\alpha, \operatorname{COX}-2$, and IL- $1 \beta$ in the presence of increasing amounts of rHMGB1 were followed by RT-PCR. $D$, Primary microglia cultures were treated with rHMGB1 (100 ng/ml), LPS (100 ng/ml), TNF $\alpha(50 \mathrm{ng} / \mathrm{ml})$, or IFN $\gamma(25 \mathrm{ng} / \mathrm{ml})$ individually or in combination for $48 \mathrm{~h}$, and $\mathrm{N} 0$ production was determined. The data of four independent experiments are presented as means \pm SEM. * $p<0.05$. Con, Control; GAPDH, glyceraldehyde-3phosphate dehydrogenase.

(Bonaldi et al., 2003). Because it is highly possible that acetylated HMGB1 has biological properties and functions that differ from released or recombinant HMGB1, it may be that HMGB1 derived from microglia exerts different effects via various signaling molecules and pathways.

The therapeutic applications of shRNA require the sustained intracellular production of shRNA in targeted tissues. Here, we demonstrate that a single administration of shRNA-expressing plasmids provided the stable expression of a silencing trigger for $>7 \mathrm{~d}$ (Fig. $2 \mathrm{~B}$ ). This is the first report to show persistent shRNA activity in the brain, although a previous report addressed the duration of interfering RNA activity in undifferentiated and differentiated P19 cells (Omi et al., 2004). Accumulating information regarding the impact of delayed neuronal death after transient global (Kirino, 1982; Abe et al., 1995) or focal (Wang et al., 2004) ischemia raises the possibility that delayed damage may be a therapeutic target. The sustained suppression of a targeted gene for $>6 \mathrm{~d}$ in the postischemic brain by a single treatment suggests that shHMGB1-pU6 might provide an effective means of controlling transient cerebral ischemia. Moreover, we have reported on efficient gene delivery using a cationic dendrimer in the brain. In this study, we found that the PAMAM-Arg dendrimer achieved transfection levels $>35 \%$ in primary cortical cultures, and these were remarkably higher than the levels obtained using commercially available reagents, such as Lipofectamine or polyethyleneimine (Kim et al., 2006). Furthermore, this effectiveness of PAMAM-Arg was observed in glial cells and in neurons (Kim et al., 2006). These results demonstrate the wide-ranging application potentials of shRNA-mediated gene modulation in the brain.

\section{References}

Abe K, Aoki M, Kawagoe J, Yoshida T, Hattori A, Kogure K, Itoyama Y (1995) Ischemic delayed neuronal death. A mitochondrial hypothesis. Stroke 26:1478-1489.

Abraham E, Arcaroli J, Carmody A, Wang H, Tracey KJ (2000) HMG-1 as a mediator of acute lung inflammation. J Immunol 165:2950-2954.

Agnello D, Wang H, Yang H, Tracey KJ, Ghezzi P (2002) HMGB-1, a DNAbinding protein with cytokine activity, induces brain TNF and IL-6 production, and mediates anorexia and taste aversion. Cytokine 18:231-236.

Andersson U, Wang H, Palmblad K, Aveberger AC, Bloom O, ErlandssonHarris H, Janson A, Kokkola R, Zhang M, Yang H, Tracey KJ (2000) High mobility group 1 protein (HMG-1) stimulates proinflammatory cytokine synthesis in human monocytes. J Exp Med 192:565-570.

Bonaldi T, Talamo F, Scaffidi P, Ferrera D, Porto A, Bachi A, Rubartelli A, Agresti A, Bianchi ME (2003) Monocytic cells hyperacetylate chromatin protein HMGB1 to redirect it towards secretion. EMBO J 22:5551-5560.

Bustin M (1999) Regulation of DNA-dependent activities by the functional motifs of the high-mobility-group chromosomal proteins. Mol Cell Biol 19:5237-5246.

Choi JS, Nam K, Kim J-B, Lee J-K, Park J (2004) Enhanced transfection efficiency of PAMAM dendrimer by surface modification with L-arginine. J Control Release 99:445-456.

DeMarco RA, Fink MP, Lotze MT (2005) Monocytes promote natural killer cell interferon gamma production in response to the endogenous danger signal HMGB1. Mol Immunol 42:433-444.

Dirnagl U, Iadecola C, Moskowitz MA (1999) Pathobiology of ischemic stroke: an integrated view. Trends Neurosci 22:391-397.

Fiuza C, Bustin M, Talwar S, Tropea M, Gerstenberger E, Shelhamer JH, Suffredini AF (2003) Inflammation-promoting activity of HMGB1 on human microvascular endothelial cells. Blood 101:2652-2660.

Giulian D (1997) Microglia and inflammatory responses. In: Primer on cerebrovascular disease (Welch KMA, Caplan LR, Reis DJ, Siesjo BK, Weir B, eds), pp117-124. San Diego: Academic.

Graham SH, Chen J (2001) Programmed cell death in cerebral ischemia. J Cereb Blood Flow Metab 21:99-109.

Huttunen HJ, Rauvala H (2004) Amphoterin as an extracellular regulator of cell motility: from discovery to disease. J Int Med 255:351-366.

Huttunen HJ, Fages C, Rauvala H (1999) Receptor for advanced glycation end products (RAGE)-mediated neurite outgrowth and activation of NF-kB require the cytoplasmic domain of the receptor but different downstream signaling pathways. J Biol Chem 274:19919-19924.

Kim JB, Piao CS, Lee KW, Han PL, Ahn JI, Lee YS, Lee JK (2004) Delayed genomic responses to transient middle cerebral artery occlusion in the rat. J Neurochem 89:1271-1282.

Kim JB, Choi JS, Nam K, Lee M, Park JS, Lee JK (2006) Enhanced transfection of primary cortical cultures using arginine-grafted PAMAM dendrimer, PAMAM-Arg. J Control Release, in press.

Kirino T (1982) Delayed neuronal death in the gerbil hippocampus following ischemia. Brain Res 239:57-69.

Kirino T (2000) Delayed neuronal death. Neuropathology 20:S95-S97.

Landsman D, Bustin MA (1993) Signature for the HMG-1 box DNAbinding proteins. BioEssays 15:539-546.

Lipton P (1999) Ischemic cell death in brain neurons. Physiol Rev 79:1431-1568.

Longa EZ, Weinstein PR, Carlson S, Cummins R (1989) Reversible middle cerebral artery occlusion without craniotomy in rats. Stroke 20:84-91.

Ombrellino M, Wang H, Ajemian MS, Talhouk A, Scher LA, Friedman SG, Tracey KJ (1999) Increased serum concentrations of high-mobilitygroup protein 1 in haemorrhagic shock. Lancet 354:1446-1447.

Omi K, Tokunaga K, Hohjoh H (2004) Long-lasting RNAi activity in mammalian neurons. FEBS Lett 558:89-95.

Park JS, Arcaroli J, Yum HK, Yang H, Wang H, Yang KY, Choe KH, Strassheim D, Pitts TM, Tracey KJ, Abraham E (2003) Activation of gene expression in human neutrophils by high mobility group box 1 protein. Am J Physiol Cell Physiol 284:C870-C879.

Park JS, Svetkauskaite D, He Q, Kim J-Y, Strassheim D, Ishizaka A, Abraham E (2004) Involvement of Toll-like receptors 2 and 4 in cellular activation by high mobility group box 1 protein. J Biol Chem 279:7370-7377.

Rosenzweig ES, McDonald JW (2004) Rodent models for treatment of spinal cord injury: research trends and progress toward useful repair. Curr Opin Neurol 17:121-131. 
Scaffidi P, Misteli T, Bianchi ME (2002) Release of chromatin protein HMGB1 by necrotic cells triggers inflammation. Nature 418:191-195.

Schmidt AM, Yan SD, Yan SF, Stern DM (2000) The biology of the receptor for advanced glycation end products and its ligands. Biochim Biophys Acta 1498:99-111.

Taguchi A, Blood DC, del Toro G, Canet A, Lee DC, Qu W, Tanji N, Lu Y, Lalla E, Fu C, Hofmann MA, Kislinger T, Ingram M, Lu A, Tanaka H, Hori O, Ogawa S, Stern DM, Schmidt AM (2000) Blockade of RAGEamphoterin signalling suppresses tumour growth and metastases. Nature 405:354-360.

Treutiger CJ, Mullins GE, Johansson A-SM, Rouhiainen A, Rauvala HME, Erlandsson-Harris H, Andersson U, Yang H, Tracey KJ, Andersson J, Palmblad JEW (2003) High mobility group 1 B-box mediates activation of human endothelium. J Int Med 254:375-385.

Tsung A, Sahai R, Tanaka H, Nakao A, Fink MP, Lotze MT, Yang H, Li J, Tracey KJ, Geller DA, Billiar T (2005) The nuclear factor HMGB1 mediates hepatic injury after murine liver ischemia-reperfusion. J Exp Med 201:1135-1143.

Wang H, Bloom O, Zhang M, Vishnubhakat JM, Ombrellino M, Che J, Frazier A, Yang H, Ivanova S, Borovikova L, Manogue KR, Faist E, Abraham E, Andersson J, Andersson U, Molina PE, Abumrad NN, Sama A, Tracey
KJ (1999a) HMG-1 as a late mediator of endotoxin lethality in mice Science 285:248-251.

Wang H, Vishnubhakat JM, Bloom O, Zhang M, Ombrellino M, Sama A, Tracey KJ (1999b) Proinflammatory cytokines (tumor necrosis factor and interleukin 1) stimulate release of high mobility group protein-1 by pituicytes. Surgery 126:389-392.

Wang W, Redecker C, Bidmon HJ, Witte OW (2004) Delayed neuronal death and damage of GDNF family receptors in CA1 following focal cerebral ischemia. Brain Res 1023:92-101.

Weise J, Engelhorn T, Dorfler A, Aker S, Bahr M, Hufnagel A (2005) Expression time course and spatial distribution of activated caspase- 3 after experimental status epilepticus: contribution of delayed neuronal cell death to seizure-induced neuronal injury. Neurobiol Dis 18:582-590.

Yang H, Ochani M, Li J, Qiang X, Tanovic M, Harris HE, Susarla SM, Ulloa L, Wang H, DiRaimo R, Czura CJ, Wang H, Roth J, Warren HS, Fink MP, Fenton MJ, Andersson U, Tracey KJ (2004) Reversing established sepsis with antagonists of endogenous high-mobility group box 1. Proc Natl Acad Sci USA 101:296-301.

Yu YM, Han P-L, Lee J-K (2003) JNK pathway is required for retinoic acidinduced neurite outgrowth of human neuroblastoma, SH-SY5Y. NeuroReport 14:941-945. 